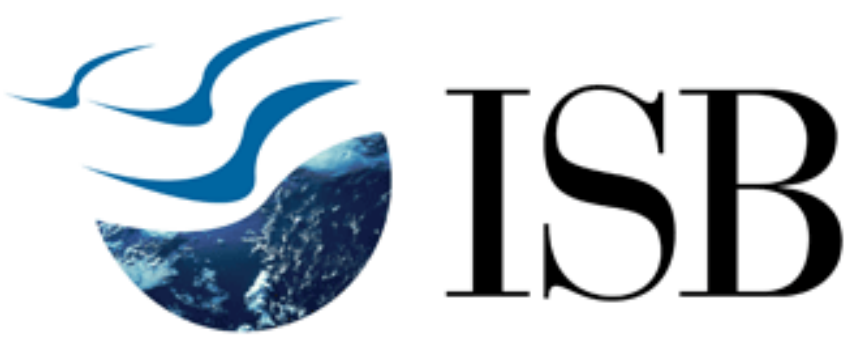

\title{
Patently Different? How Does the Strength of Patents Influence Globalization of R\&D? Empirical Evidence from the 2004 Indian Patent Reforms
}

http://eprints.exchange.isb.edu/113

Working paper

Indian School of Business

2011 


\title{
Patently different? How does the strength of patents influence globalization of R\&D? Empirical evidence from the 2004 Indian Patent Reforms
}

\author{
Anand Nandkumar ${ }^{1}$, Indian School of Business \\ anand_nandkumar@isb.edu \\ Kannan Srikanth, Indian School of Business \\ kannan_srikanth@isb.edu \\ First version: February 2010 \\ This version: April 2011
}

\begin{abstract}
There is an increasing trend for Multi-National Enterprises (MNEs) to off-shore R\&D activities to developing countries where Intellectual Property regimes (IP) are weak. Prior work in international trade theory suggests that there is limited technology transfer by MNE to destinations with weak IP regimes. However, there is considerable evidence that MNE offshore significant levels of R\&D, over and above what is required for local customization or government enforced technology transfers. In this paper, using a unique natural experiment that relates to the recently enacted patent reforms in India, we contribute towards understanding how IP regime strength influences the division of labor in technology generation activities within a firm but across locations.
\end{abstract}

JEL codes: K11, O32, 034

Keywords: IPR, division of labor of innovative labor, R\&D off-shoring

Stringent protection of foreigners' intellectual property is at odds with China's development strategy. Foreign companies operating in China complain that Beijing views the appropriation of foreign innovations as part of a policy mix aimed at developing domestic technology. Last March, the United States International Trade Commission banned imports of cast steel railway wheels made by the Chinese group Tianrui. Tianrui had hired nine employees from the Chinese licensee of Amsted Industries of Chicago, a maker of railway parts. They came with an armful of trade secrets that allowed Tianrui to muscle into the business. The New York Times Editorial "China and Intellectual Property”, 24 Dec 2010, Page A22.

\section{INTRODUCTION}

Prior work in international economics suggests that technology transfer by Multinational enterprises (MNEs) to destinations with weak Intellectual Property Regimes (IPRs) is likely to be muted. However,

\footnotetext{
${ }^{1}$ Anand thanks Vikram for research assistance
} 
there is considerable evidence that suggests that MNEs conduct a significant amount of $R \& D$ at destinations with weak IP protection despite concerns of poor IPR protection. For example, many MNEs already operate captive R\&D centers in India and China, and moreover an overwhelming percentage of new R\&D labs are set up in these two countries. ${ }^{2}$ In this paper, we study how the strength of IPRs at an offshore destination, influences division of innovative labor within a firm but across geographies.

How do MNEs manage to conduct R\&D at weak IPR destinations? There are at least two ways by which an MNE can minimize IP leakage while conducting R\&D at a weak IP location. First, MNE could involve scientists at a weak IP destination on projects that are of high private value to the MNE but not to the offshore inventor. Second, is by involving more foreign scientists on projects that do not build on pre-existing MNE knowledge. Our results complement those by Zhao (2006), who suggests a different strategy to safeguard off-shored IP. We thus highlight some management mechanisms that MNE utilize to substitute for the absence of legal IP protection. Our primary contribution is to demonstrate additional mechanisms that explain how MNE can successfully conduct R\&D in weak IPR locations.

We empirically test our hypotheses using a dataset comprising of US PTO patents assigned to US assignees that had at least one inventor based in India on it. Following Thursby and Thursby, (2006) we measure the degree to which an invention was off-shored by the ratio of India-based scientists involved in a patent. We use the recent patent reforms in India enacted in 2004 as a time shifter to test our hypotheses. We cross check our results using a novel measure of IPR strength we constructed based on how Indian courts decided IP cases. As an additional robustness check, we also draw on a survey of R\&D managers of 240 MNE R\&D centers in India and examine how their choices of project selection and management vary depending on how confident they are about the strength of the IP regime in protecting their knowledge.

We proceed as follows: the following section reviews literature while the subsequent section develops our hypotheses. We then briefly discuss the data sources used in this paper which, is followed by our empirical analysis and findings. We conclude with a discussion of our findings.

\section{LITERATURE REVIEW}

Our work draws from international economics, international business and the broader strategy literature. Prior work in international economics has mainly dealt with how the strength of IPR at a destination influences technology transfer to that destination and its consequences on global welfare. Prior work in the International Business literature also does not address how differences in the strength of IPR between the source and destination influences the nature of knowledge transferred from the source to the

\footnotetext{
${ }^{2}$ Fortune 500 firms now have 98 R\&D labs in China and 63 in India. 83\% of the new R\&D sites and 91\% of new R\&D staff added by Fortune 1000 MNE are either in China or India. Source: "Special report on innovation in emerging markets", April 17, 2010, p.4.
} 
destination. Our work considers how strength of IPR influences the nature of R\&D activity that a MNE opts to conduct at a location. As our brief literature review highlights, we contribute to the literature by clarifying that organizational practices can effectively substitute for the lack of adequate legal IP protection at a destination. While they may be a variety of organizational mechanisms such as the one that Zhao, (2006) highlights, our paper provides evidence of how MNEs effectively use project selection to minimize risks of IP leakage. To this end we build on work in the broader strategy literature that deals with how firms can appropriate value from innovations.

Prior work in international economics has dealt with how stronger IPR influences international economic activity like trade or foreign direct investment (FDI). Economists that have examined the relationship between IPR and international trade and investment (see for example Maskus and Penubarti, 1995) conclude that a stronger IPR in a developing country encourages U.S. exports to that country. Yang and Maskus (2000) found that stronger IPR regimes increase arm's length licensing by US firms with firms in the destination country. Bransetter, Fisman and Foley (2004) test the impact of change in IPR on technology licensing by MNE in a unique longitudinal dataset of US MNEs and find a positive correlation between strength of IPR and technology transfer. Our paper differs from these studies in several ways.

First, the literature concludes that a strong IPR is critical for technology transfer from a MNE to its subsidiary. It sheds very little light on the magnitude of R\&D that is conducted by MNE in countries with weak IPR locations. We do not assume that strong IPRs are necessary and highlight a few organizational mechanisms that enable MNEs to conduct R\&D at a location with weak IPRs. Second, it also appears that most studies assume that the nature of technology that is transferred to the developing country is either technology that enables these destinations to inexpensively manufacture the end product (Bransetter, Fisman and Foley, 2004) or to customize products for domestic markets (Mansfield, Teece and Romeo, 1979; Kummerle, 1999). In contrast, we focus only transfer of technology insofar as it relates to $R \& D$ activity of a MNE aimed at a global product (as opposed to R\&D aimed at local customization). Our goal is to explain how MNEs manage to conduct globally relevant R\&D in destinations with weak IPR. As we will describe in detail later, one of our empirical tests focuses on how strength of IPR determines the extent to which a MNE transfers upstream technology inputs required to generate downstream innovations. We empirically focus on within firm effects. We test how the strength of IPR influences the division of innovative labor between scientists located in India versus elsewhere on innovations that require higher degree of upstream MNE specific technology inputs versus those that require fewer upstream inputs

Prior work in International Business (IB) literature that relates to managing R\&D in MNEs can be roughly divided in two strands. The first strand examines MNE R\&D location decisions and concludes 
that that there a variety of reasons for MNEs to conduct R\&D in a foreign location, broadly classified as demand side and supply side factors. While supply side factors include considerations such as access to cheap skilled labor or knowledge from local clusters, demand side factors include market potential, need for customization, market sophistication and political considerations. Based on these factors several authors have built a variety of typologies to classify the nature of R\&D activity performed at subsidiaries (see Kuemmerle, 1996; Ronstadt, 1977;Hakanson and Nobel, 1993; Ghoshal, 1986). In contrast to this work, we do not examine the factors that determine the choice of a location. We take the location decision as given and then examine how the strength of IPR at that location influences the type of R\&D conducted at that location.

The second strand of IB work deals with strategies MNEs adopt to transfer knowledge between headquarters and subsidiaries. More generally, the IB literature concludes that the ability of MNEs to leverage knowledge across geographies is critical for competitive advantage (Gupta and Govindarajan, 1991; Mudambi, 2002, 2007; Piscitello, 2004). In spirit of this conclusion, a large body of work in this strand focuses on the mechanisms that facilitate knowledge transfer between MNEs and their subsidiaries (cf: Szulanski, 2000). A preponderance of empirical work in this strand barring a few exceptions, (such as Yang, Mudambi and Meyer, 2008) focuses on knowledge transfer between two locations that are located in developed economies presumably having similar IPRs. Our focus however is on how differences in the strength of IPR between locations influence which types of knowledge to transfer.

Scholars in the strategy literature have also examined how the strength of IPR influences the nature of trade in technology between firms. Based on the insight of Arrow (1962)that ideas face a revelation problem, much prior work concludes that division of innovative labor between firms cannot exist in the absence of legal protection. The literature on Markets for Technology (MFT) expands on this insight and shows that stronger patent regimes promote arms length contracting for technology (see Arora, Fosfuri, and Gambardella, 2004 for a review).

In contrast, prior work on innovation in the broader strategy literature shows that firms typically use a variety of mechanisms to prevent IP from spilling over to competitors and that relying of legal means to protect IP is not often the norm in many industries (Cohen et al, 1987; Levin et al, 1987). Prior work has shown a number of conditions under which innovators can appropriate value from an innovation even in the absence of legal IP protection. For example, ownership of specialized and co-specialized complementary assets (Teece 1986; Gans and Stern 2000) or connection to related products or services (Anand and Galetovic, 2004) can enable firms to appropriate value from an innovation even under weak IPRs. Prior work also shows that under such conditions, arms-length contracting for "know-how" can happen between firms even in the absence of legal IP protection for know-how (Arora, 1996; Anton and Yao, 2002). 
In contrast to the above body of work, our work does not focus on direct threats of expropriation from a competitor or a potential licensor. Instead, we focus on "indirect" threat of expropriation, or the possibility of MNE's IP leakage through foreign employee mobility (as illustrated by our opening vignette). We build on these insights that division of innovation labor between firms can occur in the absence of IP protection and apply it to the division of innovative labor within a firm, but across geographies with different degrees of IP protection.

In sum, to our knowledge, the literature thus far, has not examined how the strength of IPR at the subsidiary's location influences the nature of $R \& D$ that is conducted at that location, with the notable exception of Zhao (2006). Zhao, (2006) argues that offshored R\&D projects with strong links with other projects conducted elsewhere under strong IPR (or projects with strong internal linkages) are likely to have lower risk of IP leakage. A strongly connected project is less valuable per se to an imitator, unless combined with other knowledge held elsewhere within the MNE. Using a set of cross-country regressions she shows that R\&D destinations with weaker IPRs are more likely work on innovation projects with stronger internal linkages.

We propose an alternative, albeit not mutually exclusive, mechanism that explains how MNEs manage to conduct R\&D at destinations with weak IPR. Our thesis is motivated by a key characteristic that appears to be a common practice among MNEs off-shoring R\&D projects to Indian captives. Almost all MNEs captive managers that we interviewed for this study said that their Indian captive center had full responsibility for $\mathrm{R} \& \mathrm{D}$, product development and support for some global products, with minimal involvement from the headquarters. Interestingly, the practice of offshoring entire products they said was a norm even prior to the Indian patent reforms in 2004. ${ }^{3}$ Moreover, some even claimed that some products sold globally were conceived, designed and developed at their India captive center. A few said that engaging in product development of almost the entire product was necessary to recruit and retain highly skilled R\&D staff. The following vignette from Adobe India exemplifies:

Adobe India is NOT an offshore development center where work is outsourced. It is a Development centre, which has teams working on various features of the main product in partnership with the other development centers. The level of ownership enjoyed by the teams is different for each product line. ${ }^{4}$

Based on our interviews, we argue that there are at least two ways by which an MNE can minimize IP leakage. First a MNE manager can decide to offshore projects that are firm specific projects that are of high private value to the MNE but not to the offshore inventor. Second, a MNE

\footnotetext{
${ }^{3}$ In 2004, India enacted patent reforms that made its patent act in compliance with the mandate of the World Trade Organization

${ }^{4}$ http://www.adobeindia.com/work/faqs.html (date accessed: 3 April, 2011); our emphasis.
} 
manager can minimize the risk of IP leakage by off-shoring projects that do not build on pre-existing MNE knowledge.

Our work thus offers guidance regarding how MNE managers should organize R\&D when a project involves collaboration with scientists located in a country with a weak IPR. Moreover, also note that our main focus is not the main effect i.e. we do not focus on how stronger IPR at a location influences the volume of $R \& D$ conducted at that location. Although we do state it as a hypothesis, this is not the main goal of this work. Rather, our main focus is on how the strength of IPR influences the type of $R \& D$ conducted at the offshore location.

\section{MODEL}

We develop a simple model to guide the empirical analysis. Our goal is to argue that the strength of patent protection has differential effects on offshoring different types of $R \& D$, proprietary versus nonproprietary and radical versus incremental, as gathered from our interviews. To facilitate exposition we will refer to a scientist at a location that has weak IP protection as an "offshore" scientist. Analogously we will refer to a scientist that is located in a country that has strong IP protection as a local scientist. Similarly, we will also henceforth refer to the location with weak IPR as the "offshore" location. Finally we will often refer to a $R \& D$ project that employs both local and offshore scientists as a distributed $R \& D$ project.

We motivate our model using a familiar tradeoff: a MNE manager has to balance the advantage of lower costs of doing $R \& D$ at the offshore location with the increased risk of IP leaking out to current or potential competitors. With an eye on empirics that follows, our unit of analysis is an R\&D project. Also, following Thursby and Thursby, (2006) we measure the degree to which an invention was off-shored by the proportion of Indian scientists involved in a patent.

We proceed as follows. We first describe how the level of patent protection changes the ratio of local and offshore scientists employed on project using a base case which considers an innovation that uses little prior MNE knowledge and an innovation with low firm-specificity. We then consider the case of an innovation with high use of prior MNE knowledge and compare the effects of stronger patent protection on the ratio of foreign scientists that the focal MNE opts to engage to generate the innovation. Finally we consider a case in which the focal innovation with high firm specificity

\subsection{Setup}

Suppose distributed R\&D generated by a MNE depends on two types of firm inputs, the amount of effort expended by offshore scientists $\mathrm{N}$, and the amount of effort expended by local scientists E. For ease of exposition, we assume away any incentive problems that could affect the amount of effort expended by the scientists involved in the project. Further, we also assume away any differences in 
marginal productivity among scientists within a location. With these simplifying assumptions, one can think of $\mathrm{N}$ as just the number of offshore scientists employed at the offshore location and $\mathrm{E}$ as the number of local scientists involved in a R\&D project.

Since our goal is to examine how the strength of patent protection at the offshore location influences the extent to which a MNE distributes different types of R\&D, we assume that the extent of patent protection is near perfect at the MNE (local) location. Let $0 \leq \theta \leq 1$ denote the strength of patent protection in the offshore location. A higher $\theta$ implies a higher level of patent protection. Let $\mathrm{V}(\mathrm{E}, \mathrm{N})$ denote the expected private value of the innovation to the MNE, with both $\mathrm{E}$ and $\mathrm{N}$ increasing and concave in $\mathrm{E}$ and $\mathrm{N}$.

Costs:

There are two cost components associated with employing offshore scientists in a project. First, is the cost of labor which is $\alpha$, per unit of effort incurred by the offshore scientist. The second is the cost associated with IP leakage which arises from the possibility of an offshore scientist expropriating value from the idea that is being invented by excluding the MNE. This cost depends on the underlying probability that each foreign scientist involved in the project steals the idea $p(\theta)$ and the number of scientists N. Since stronger IP laws are likely to discourage the offshore scientist from privately benefiting from the idea, $\mathrm{p}_{\theta}<0$. Further $\mathrm{p}(0)=1$ and $\mathrm{p}(1)=0$. Given the possibility of IP leakage, the expected benefit to the firm from the distributed innovation is just $\mathrm{V}(\mathrm{E}, \mathrm{N})(1-\mathrm{p}(\theta))^{\mathrm{N}}$ where the second term is just the probability that none of the southern scientists privately benefit from the innovation. Finally we denote the cost per unit of effort of local scientist's by $\mathrm{C}$. We assume that local scientists are more expensive than offshore scientists i.e. $\mathrm{C}=\mathrm{k} \alpha$ where $\mathrm{k}$ is a constant $>1$. Note that this assumption is not crucial for our results although it makes the model simpler. The expected profit from the distributed innovation is thus given by

$$
\Pi=V(E, N)(1-p(\theta))^{N}-C E-\alpha N
$$

The objective of an MNE R\&D manager is to optimally choose $\mathrm{N}$ and $\mathrm{E}$ to maximize profits from the distributed innovation. The first order conditions are given by

$$
\begin{gathered}
\frac{\partial \Pi}{\partial E}=V_{E}(1-p(\theta))^{N}=C \\
\frac{\partial \Pi}{\partial N}=(1-p(\theta))^{N} V_{N}+V(E, N)(1-p(\theta))^{N} \ln (1-p(\theta))=\alpha
\end{gathered}
$$

Using $\mathrm{C}=\mathrm{k} \alpha$, the first order conditions can be written as

$$
\begin{aligned}
& \frac{\partial \Pi}{\partial E}=(1-p(\theta))^{N}\left[V_{E}-k V_{N}-V \ln (1-p(\theta))\right]=0 \\
& \frac{\partial \Pi}{\partial N}=(1-p(\theta))^{N}\left[k V_{N}+k V \ln (1-p(\theta))-V_{E}\right]=0
\end{aligned}
$$


We state all our results in term of the ratio of offshore scientists involved in the distributed R\&D project, denoted by $\Phi$. We first show that $\mathrm{N}$ is increasing in $\theta$, and $\mathrm{E}$ is decreasing in $\theta$. Hence an increase in $\theta$ increases $\Phi$ (proofs in appendix). Tightening patent laws in the foreign location thus is likely to increase the share of foreign scientists involved in an $R \& D$ project. Conditional on off-shoring a $R \& D$ project to a foreign country, the ratio of foreign scientists involved in a R\&D projects is likely to be higher when IP is stronger.

Result 1: $\Phi$ is increasing in $\theta$. The proportion of offshore scientists involved in a distributed $R \& D$ project is higher under a stronger patent regime.

Our baseline hypothesis above is consistent with prior work in international economics that suggests that technology transfer by MNEs to the offshore location with weak IP regimes is likely to be muted (Maskus and Penubarti, 1995; Bransetter et al, 2004). Also, prior work in MFT also suggests that there is likely to be limited trade in technology under weak IP regimes (cf: Arora et al, 2004).

Innovations that use high vs. low levels of prior MNE knowledge

We define an innovation to be incremental (to the firm) if it builds on MNE specific knowledge. While collaboratively producing an incremental innovation with offshore scientists a MNE not only endangers the focal innovation, but it also endangers the MNE's upstream knowledge that the focal innovation builds on. If it is true that knowledge that is transferred by a MNE to its subsidiary is more amenable to leakage (Kogut and Zander, 1995), an incremental innovation that builds on a MNE's existing knowledge base should present a greater risk of leakage of pre-existing knowledge. It should hence be cheaper for a MNE to engage a offshore scientist on a non-incremental R\&D project that does not expose the firm's pre-existing knowledge base to leakage. This in turn implies that an MNE is likely to hire more offshore scientists on a non-incremental innovation (radical to the firm) rather than on an incremental innovation when IPR is weak. When IPR is strengthened in the offshore location, the threat of expropriation by the offshore scientist diminishes. It follows that when IPR is stronger, the MNE will involve more offshore scientists in an incremental innovation relative to when IPR was weak. Strengthening IP protection is likely to matter less for non-incremental innovations that do not endanger prior MNE knowledge to leakage.

In order to incorporate this idea, we denote $\tau g\left(1-(1-p(\theta))^{N}\right)$ as the expected cost of leakage of prior knowledge where $\tau$ represents the amount of upstream prior knowledge held by the MNE that is involved in the R\&D project and $\mathrm{g}$ the loss in the event of such knowledge leaking out to a competitor. $\left(1-(1-p(\theta))^{N}\right)$ is just the probability that the offshore scientists expropriate prior firm specific knowledge. The expected profit from the distributed incremental innovation project is just

$$
\Pi=V(E, N)(1-p(\theta))^{N}-C E-\alpha N-\tau g\left(1-(1-p(\theta))^{N}\right)
$$


The first order conditions are now given by,

$$
\begin{aligned}
& \frac{\partial \Pi}{\partial E}=(1-p(\theta))^{N}\left[V_{E}-k V_{N}-(V+\tau g) \ln (1-p(\theta))\right]=0 \\
& \frac{\partial \Pi}{\partial N}=(1-p(\theta))^{N}\left[k V_{N}+k(V+\tau g) \ln (1-p(\theta))-V_{E}\right]=0
\end{aligned}
$$

$\Phi$ is now smaller in the case of an incremental innovation. Stated otherwise, $\Phi$ is decreasing in $\tau$ (proof in the appendix). There is likely to be fewer offshore scientists involved in an incremental innovation relative to a non-incremental innovation.

Result 2: $\Phi$ is decreasing in $\tau$. The proportion of offshore scientists is lower in the case of an incremental innovation relative to a non-incremental innovation.

The effect of $\theta$ on $\Phi$ is higher in the case of incremental innovation (proof in appendix). This is because an increase in $\theta$ also additionally decreases cost of leakage of prior knowledge that the focal innovation builds on. Thus $\theta$ increases the ratio of offshore scientists by more in the case of an incremental innovation relative to a non-incremental innovation. We state this result formally below as result 3 .

Result $3: \frac{\partial^{2} \Phi}{\partial \theta \partial \tau}>0$. Strengthening patent protection increases the proportion of offshore scientists by more for incremental innovations relative to non-incremental innovations.

\section{$\underline{\text { High vs. low firm-specific innovations }}$}

We define an innovation as proprietary to the MNE if it is relatively more privately valuable to the MNE than it is to the scientist, or to a competitor. Proprietary innovations are likely to be less valuable to an offshore scientist or to competitors and hence are less likely to be expropriated. This is because of at least two reasons. First, with proprietary innovations, competitors may not have the absorptive capacity to make use of such knowledge (Cohen and Levinthal, 1990; Zahra and George, 2002). Hence, a scientist that intends to profit from licensing or selling off the expropriated idea to a competitor may just not be able to attract buyers. Second, proprietary innovations may require specialized complementary assets for commercialization (Teece, 1986; Anand \& Galetovic, 2004) which may be too expensive for either the scientist or a competitor to acquire. MNEs are hence likely to face a lower risk of leakage with such innovations.

Let $0 \leq \delta \leq 1$ denote how proprietary the focal innovation is to the firm. Higher values of $\delta$ are associated with more proprietary innovations. We assume that $\delta$ directly influences how likely the focal innovation will leak out to existing or potential competitors through the offshore scientist. We now assume that $\mathrm{p}$ is a function of both $\theta$ and $\delta$, so that $(1-\mathrm{p}(\theta, \delta))^{\mathrm{N}}$ is the probability of non-leakage of the focal innovation. Further, we assume that $\mathrm{p}_{\delta}<0$. As before the expected private value to the firm from the 
innovation is just $\mathrm{V}(\mathrm{E}, \mathrm{N})(1-\mathrm{p})^{\mathrm{N}}$. The expected profit from the distributed innovation taking into account the level of firm specificity is:

$$
\Pi=V(E, N)(1-p(\theta, \delta))^{N}-C E-\alpha N
$$

$\Phi$ now is larger when the focal innovation is proprietary than when it is non-proprietary. While both $\mathrm{N}$ and $\mathrm{E}$ are increasing in $\delta$, the increase in $\mathrm{N}$ is more than increase in $\mathrm{E}$, resulting in $\Phi$ increasing in $\delta$ (proof in the appendix). It is thus likely that an MNE will employ greater number of offshore scientists on a proprietary innovation than on a non-proprietary innovation.

Result 4: $\Phi$ is increasing in $\delta$. The proportion of offshore scientists is higher in the case of proprietary innovations.

Moreover $\Phi$ is less sensitive to a change in $\theta$ for proprietary innovations (proof in appendix). This is because the marginal benefit to the firm with an increase in $\theta$ is lower in the case of proprietary innovations relative to non-proprietary innovations. Thus $\theta$ increases the proportion of offshore scientists by less in the case of proprietary innovations. Thus as is formally stated in result $5, \theta$ increases the proportion of offshore scientists by less in the case of proprietary innovations.

Result 5: $\frac{\partial^{2} \Phi}{\partial \delta \partial \theta}<0$. Strengthening patent protection increases the proportion of offshore scientists by less for proprietary innovations.

\section{DATA AND VARIABLES}

We test our hypotheses using data on patents granted by the USPTO filed between 1973 and until 2009 that had at least one Indian inventor, but were held by non-Indian assignees. Our unit of observation is a patent. Of a total of 5712 U.S. patents held by U.S. assignees, we dropped 234 patents that were assigned to U.S. universities and 90 patents that were assigned to U.S subsidiaries of Indian MNEs. This leaves us with 5441 patents that we use in our empirical analysis.

Before explaining our measures in detail, we provide a brief background of the main changes to the Indian patent law over the last 40 years. After attaining independence from British rule in 1947, India opted to continue with the British Patents and Design Act of 1911 until 1972. Under this statute, firms could patent both processes as well as, products for 14 years. In order to facilitate acquisition of indigenous industrial capability, especially in the pharmaceutical sector, the Government of India enacted a law that significantly weakened the IPR in 1972. Some of the major changes in the 1972 act were shortening the life of process patents to 5-7 years and the banning of product patents.

In 1994, the Indian government signed the Agreement on Trade Related aspects of Intellectual Property Rights (TRIPs treaty) and by doing so, committed to a path of reform that would eventually produce a patent statute consistent with the standards outlined in the new TRIPs agreement. India 
effectively took a decade, the maximum available time under the agreement to comply with TRIPs and did so when it enacted the patent act in 2005 (applicable retrospectively from 1 Jan, 2004). The 2005 law once again allowed patenting products as well as processes for a term of 20 years from the date of filing and for the first time allowed the patenting of software. Furthermore the 2005 legislation also paved way for the setup of a specialized judiciary to hear IP cases, through the setting up of the Intellectual Property Appellate Board (IPAB). ${ }^{5}$ These changes along with the possibility of filing international patent applications under the Paris Convention Treaty (PCT) from India provide relatively stronger IP protection since 2004. Our goal is to understand how these reforms changed the way MNE R\&D projects are managed.

We use two events to test our hypotheses: the first event was when India accepted the TRIPs mandate in 1995. The second event is the year in the Indian patent law came into effect in 2004. These events provide us with a natural experiment to test our hypotheses. As we will explain in detail later, we use these two events to tease out any changes in the division of innovative labor between offshore and local scientists after the patent reform relative to before the reform depending on the nature of the focal innovation.

Our key premise is that both the intent to confirm to TRIPs and the eventual enactment of the legislation in accordance with the TRIPs mandate acted as a key deterrent for the Indian (foreign) scientists from expropriating IP belonging to the MNE. As further support to our empirical design figure 1 shows that there was a significant jump in the ratio of foreign (Indian) inventors to the number of local inventors on a patent in years 1994 and 2004.

\section{<Insert figure 1 here>}

Our unit of observation is a patent. We mapped each patent to a three digit SIC code using concordance used in Silverman, (1999). ${ }^{6}$ This procedure enabled us to assign each patent to an industry. Of a total of 5441 patents, 2303 patents relate to the Information and Communication Technology (ICT) industry, 1014 patents relate to biotechnology and pharmaceutical industries, 199 relate to the chemical industry. ${ }^{7}$ Table 1 provides a break up by year filed of granted patents that relate to the different industry segments. We also collected control variables such as size of firms, R\&D expenditure and sales from COMPUSTAT database by matching assignee name on a patent with firm names in the COMPUSTAT database. We now describe the empirical measures in detail.

\footnotetext{
5 These courts came into being in middle of 2004.

${ }^{6}$ To do so, we first mapped the IPC classification on every patent with Canadian SIC codes using one of the intermediate files available at www.rotman.utoronto.ca/ silverman/ipsic/documentation_IP-SIC_concordance.htm. We then matched the Canadian SIC codes with US.SIC codes using another file available in the abovementioned web site.

7 The remaining 483 patents relate to automobiles and transportation (95), food and agriculture (118), paper (47), leather (53), metals (105), manufacturing (64), electrical (54)and engineering industries (42).
} 


\section{<Insert table 1 here>}

\section{Ratio of foreign scientists to local scientists:}

The key dependent variable is the ratio of Indian inventors, on a focal patent (ratio inventors henceforth). We constructed this variable by first counting the total number of Indian inventors on a patent using the inventor location listed on the focal patent. From the internet, we acquired a list of all Indian cities. ${ }^{8}$ We then determined if an inventor on a patent was from India by matching the location listed for every inventor on a focal patent with the constructed list of Indian cities. We also counted the total number of non-Indian inventors listed on every patent. We then calculated this variable by dividing the number of Indian inventors over the number of non-Indian inventors. Note however that we use the natural $\log$ of this variable in our regressions, (henceforth referred to as $\log R$ ). This variable is the difference between the (1+) natural log of the total number of Indian inventors and (1+) natural $\log$ of total number of non-Indian inventors listed on the patent. ${ }^{9}$

\section{Strength of IPR:}

We develop two time-based proxies for the strength of the IPR. Our principal results are based on a two dummy variables that reflect the two main events that affected the strength of the patent law in India. The first dummy variable, Period I dummy=1 if the focal patent was filed on or after 1994 but before 2003 and 0 otherwise. The second dummy variable, Period II dummy $=1$ if the focal patent was filed on or after 2004 and 0 otherwise.

As a robustness check, we created an alternative measure of IPR strength using the percentage of cases that were decided in favor of the IP holder (in log, just proportion for henceforth). This is calculated as the total number cases that were decided in favor of the IP holder divided by the total number of patent, trademark and copyright cases that were filed before the high court, supreme court or the IPAB. We cross check our principal results with this alternative measure for strength of IP. Our principal results are qualitatively unchanged to the choice of the variable that proxies for the strength of the IPR.

\section{Incremental innovation:}

Since incremental innovations to the firm are more likely to build on firm specific prior art, we use the number of self backward citations to proxy for the incrementalness of the focal patent. In order to construct this measure, out of the total backward citations to the focal patent, we calculated the total number of backward citations that were made by the same assignee. Our measure is based on the fact that patents with more backward self citations more likely build on firm specific prior art and likely to result in an incremental innovation. In our regressions, we use the log (1+number of backward citations) to

\footnotetext{
8 (http://en.wikipedia.org/wiki/List_of_cities_and_towns_in_India)

${ }^{9}$ Since some patents had no non-Indian inventors, we use the difference between the natural log of the total number of Indian inventors and (1+) natural log of total number of non-Indian inventors listed on the patent. Our results are qualitatively unchanged if we use the share of Indian inventors as a dependent variable.
} 
patents belonging to the same firm to whom the focal patent also belongs to, henceforth referred as $\log (1+$ self backward cits. $)$.

\section{Proprietary innovation:}

We use the ratio of the number of forward citations made by the same assignee on the focal patent (selfforward citations) to the total number of forward citations made by other assignees (other forward citations), as a measure of how proprietary the focal innovation is, to the firm (we shall refer this variable as (ratio forward citations, henceforth). Since the number of forward citations are typically sensitive to the age of a patent, we weight the both self forward citations and other forward citations by the average number of forward citations pertaining to the focal patent's age cohort.

We constructed this variable as follows: we first found out the number of forward citations to a focal patent that were made by one or more patents belonging to the same assignee. For each patent, we then calculated the average number of forward self citations for all patents that were granted during the same year (average forward self citations). We then calculated weighted forward self citations by dividing self forward citations by average forward self citations. Likewise, we also calculated weighted other forward citations based on other forward citations. Our measure of proprietaryness is the ratio of weighted forward self citations to weighted forward other citations. In regressions we however estimate separate coefficients for $\log (1+)$ forward self citations and $\log (1+)$ weighted forward other citations respectively.

\section{Controls:}

Other backward citations: In our regressions we also control for the incremental nature of an innovation in general using $\log (1+$ other backward citations). This is the number of patents (in $1+\ln )$ owned by other firms that are cited by the focal patent.

Industry dummies: Our mapping between each patent to a two digit SIC code provides us with the ability to control for any industry effects that may influence the proportion of Indian scientists on an innovation. We use 4 industry dummies, ICT, medical, electronics and chemical and plastics dummies to control for such industry effects. The left out category are patents that pertain to industries other than these. As table 1 shows, these 4 industry dummies account for a majority of the patents (about $89 \%$ ) of all patents in our dataset. Also specifications that use two digit SIC code dummies instead of the abovementioned industry dummies yield qualitatively similar results.

Firm fixed effects: We also control for firm specific effects that might influence division of labor between MNEs and Indian subsidiary by using 123 firm fixed effects. The left out category comprising of $556(10 \%)$ patents are those that predominantly belong to small startups that do not offshore R\&D to India frequently. 


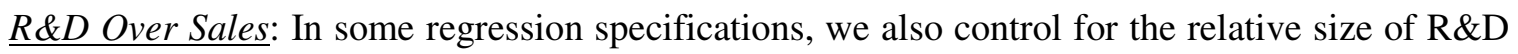
budgets of a focal firm using R\&D over sales, which is the dollar amount of R\&D incurred by a firm in a year divided by total sales for that firm (R\&D over sales). Since all firms do not report R\&D and/or sales in our dataset we lack this measure for 556 patents that predominantly belong to entities that not publicly listed and hence not available in COMPUSTAT. In regressions in which we use this measure we control for missing values using $R \& D$ not reported dummy $=1$ if $R \& D$ or sales for the focal assignee is missing.

Size: In some regression specifications, we also control for the size (log size, henceforth) of focal firm using the number of employees of the firm in $(1+\mathrm{ln})$. We lack this measure for 556 observations for reasons outlined above.

$\underline{P C T}$ : PCT $=1$ if the assignee on the focal patent filed the patent as a PCT patent (PCT dummy). Since PCT patents are typically filed in more than a single country they may just be more valuable to an assignee.

$\underline{\text { US assignee }}$ : is a dummy variable $=1$ the assignee on a patent was a U.S assignee and 0 otherwise (US assignee dummy, henceforth).

Since both our measures of IPR strength vary only over time, we use a variety of controls to account for other macroeconomic events that may influence how innovative labor is divided between the Indian offshore location and headquarters.

Proxies for the supply of scientific talent: We use the number of engineering colleges per million (engg. coll.) and the number of PhDs awarded (PhDs) per year per million in India as proxies for the supply of scientific talent in India. As the name suggests these variables denote the number of engineering colleges per million Indian residents and the number of PhDs per million Indian residents respectively. In addition in certain specifications, we also use the number of patents filed by Indian residents at the Indian Patent office per million as an additional proxy (resident patent applications) for the amount of scientific talent in India instead of the other two proxies mentioned above.

Proxy for the size of Indian market opportunity: We also control for the size of the Indian market opportunity using the number of Indian trademarks filed in India by Indian residents as a proxy for the size of the Indian market opportunity (Resident Indian trademarks) . Larger markets may attract lots of foreign products many of which may need customization to suit local tastes and preferences. Hence, large offshore markets could just attract more customization work. Though it is unclear why the firm would file a patent application in the USPTO to protect local customization type innovations, we do control for this possibility using the number of Indian trademark applications by Indian residents per million. Alternatively using GDP per capita, as a proxy for the size of the Indian market opportunity leaves our results unaltered (GDP per capita). 
Proxy for complexity of the innovation: In certain specification we control for the complexity of the innovation using proxies that are based on the total number of inventors assigned on the patent. More precisely we use 3 dummy variables: low inventor dummy=1 if the total number of inventors on the patent is less than or equal to two, intermediate inventor dummy $=1$ when the total inventors on the patent were between three and five, and high inventor dummy=1 when the total inventors on the patent exceed five.

Descriptive statistics for all of the independent variables are included in Table 2.

\section{<Insert Table 2 here>}

\section{EMPIRICAL SPECIFICATION AND RESULTS}

Our goal is to examine how ratio of offshore inventors on an R\&D project varies with changes in the strength of IPR, radicalness and proprietaryness of the project. Suppose

$$
\text { ratio inventors }_{i j p}=\beta_{0}+\beta_{1} \text { proprietaryness }_{p}+\beta_{2} \text { radicalness }_{p}+\theta_{1} X_{i}+\theta_{2} Z_{p}+\theta_{3} K_{t}+\varepsilon_{i j p}
$$

where $X_{i}$ include controls that vary only by assignee such as assignee fixed effects and foreign assignee dummy and $Z_{p}$ includes controls that vary only by patent such as pct dummy and $K_{t}$ are controls that vary by filing year.

Our theory suggests that $\beta_{1}>0$ and $\beta_{2}>0$. Recall that we use backward self citations as a proxy for radicalness and ratio forward citations as a proxy for proprietaryness of a patent. We start with providing evidence for our hypotheses using simple comparison of means. In table 3A, we first compare how the Indian patent reform shifted ratio inventors on a patent. From columns 5 and 6, consistent with result 1, we find that the ratio inventors on a patent were higher by about 0.71 in period I and by about 0.31 in period II.

\section{$<$ Insert table 3A here $>$}

In table $3 \mathrm{~B}$, we compare how the incrementalness of a $\mathrm{R} \& \mathrm{D}$ project influences ratio inventors on a MNE patent. To this end, we classify patents in our sample as those with "high" number of self backward citations or "low" depending on whether the number of self backward citations on the patent was above or below the mean number of backward self citations. Table 3B shows that for patents that had "high" number of backward self cites, the ratio inventors was significantly higher in period III than in period II and higher in period II than in period I (3.41 vs. 5.83 and 5.83 vs. 6.36). In the "low" category however, there is no significant increase in ratio of Indian scientists (5.79 vs. 6.28 and 6.28 vs. 6.41). Note, that in all the 3 periods, patents that are more incremental have lower ratio inventors than those that are non-incremental to the firm. All of these broadly confirm results 2 and 3.

\section{$<$ Insert 3B here>}

In table $3 \mathrm{C}$, we compare how the proprietaryness of an innovation affects the proportion of Indian scientists employed in an innovation by the MNE. As with incrementalness, we classify patents in our 
sample as those with "high" or "low" proprietaryness depending on whether ratio forward citations was above or below the mean number of forward self citations. Table $3 \mathrm{C}$ shows that before reforms, patents that have "high" ratio forward citations have a higher ratio of Indian inventors relative to patents with "low" ratio forward citations. From table 3C the ratio inventors was about 0.91 more in period I, 0.57 more in period II and 0.13 more in period III. These lend support to results 4 and 5 .

\section{$<$ Insert 3C here $>$}

The non-parametric analysis above supports our hypotheses, but does not control for a variety of other factors. Accordingly, we turn to regressions. We opt to estimate a log transformed version of equation (10). ${ }^{10}$ Given our proxies for radicalness and proprietaryness our estimation equation is

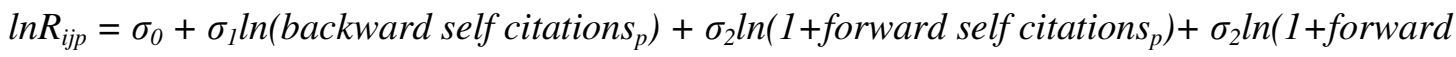

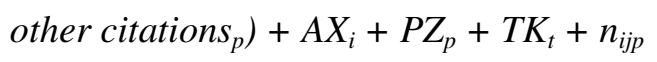

where $\ln R_{\mathrm{ijp}}=\ln \left(1+\right.$ Indian inventors $\left._{\mathrm{p}}\right)-\ln \left(1+\right.$ non-indian inventors $\left.\mathrm{p}_{\mathrm{p}}\right)$. Our empirical strategy is to examine how ratio inventors on a patent $\mathrm{p}$ filed by an assignee i relating to industry $\mathrm{j}$ filed at time $\mathrm{t}$ changes after the IPR was strengthened relative to when it was weak. To this end we compare how ratio inventors changed on patents that were filed when India signed to TRIPS in 1994 and when the new patent law was legislated in 2004 relative to patents that were filed prior to 1994. We first explore the average effects of the reform in table 4 . To this end, we estimate

$$
\begin{aligned}
& \ln R_{i j p}=\delta_{0}+\tau_{1} \text { Period } I_{t}+\tau_{2} \text { Period } I I_{t}+\rho_{1} \ln \left(\text { backward self citations } s_{p}\right)+\rho_{2} \ln (1+\text { forward self } \\
& \text { citations } \left._{p}\right)+\rho_{3} \ln \left(1+\text { forward other citations } s_{p}\right)+\Phi_{1} X_{i}+\Phi_{2} Z_{p}+\Phi_{3} K_{t}+\eta_{i j p}
\end{aligned}
$$

Result 1 suggests that $\tau_{1}<0$ and $\tau_{2}<0$ (the omitted category is patents filed after 2004). Moreover, result 2 suggests that $\rho_{1}<0$ and result 3 suggests $\rho_{2}-\rho_{3}>0$. We estimate (12) using OLS. In specification 1 , of table 4, we start with controlling for assignee specific factors using 123 assignee fixed effects in addition to 4 industry dummies, pharmaceuticals, ICT, chemicals and electronics (includes hardware and semiconductors)

In addition we use a variety of time-varying controls: we control for the availability of innovative labor in India using the number of engg. coll. and $P h D s$ and for the size of the market opportunity in India using GDP per capita. In specification 2, we use resident patent applications and resident Indian trademarks instead of the time varying controls in specification 1 to proxy for the availability of scientific talent and the size of the market opportunity in India respectively. In specification 3, we add 2 SIC digit fixed effects instead of the industry dummies in specification 1 , and in addition control for $R \& D$ over sales and MNE size using log(employees). Since 22 assignees (556 obs. in all) do not report R\&D budgets we control for missing values using $R \& D$ not reported dummy and interact $1-R \& D$ not reported dummy

\footnotetext{
${ }^{10}$ We estimate log transformed version in order to estimate separate coefficients for $\ln (1+$ selfforward citations) and $\ln (1+o t h e r$ forward citations)
} 
with $R \& D$ over sales. We also follow a similar procedure for our size variable to deal assignees do not report their size. In specification 4, we additionally control for the complexity of the invention using 3 more dummies: low inventor, intermediate inventor and high inventor dummies. Results are shown in table 4.

\section{$<$ Insert 4 here >}

Results of specifications 1 through 4 suggest that the proportion of Indian inventors was higher after the reform than before it. For instance, results of specification 1 suggest that when compared to a patent filed in period III, a patent that was filed in period I had a $16 \%$ lower ratio inventors, on average. Similarly ratio inventors was about $12 \%$ lower on an average on patents that were filed in period II relative to a patent that was filed in period III. Results also suggest that more radical (to the MNE) and proprietary innovations are likely to have higher ratio inventors. From specification 1, for instance a patent that has 1 standard deviation higher backward self citations is likely to have about $12 \%$ lower ratio inventors. Similarly on a patent that is about 1 standard deviation more proprietary is likely to have about $7 \%$ higher ratio inventors. These findings support results 1, 2 and 4.

Specification 2 shows that using resident patent applications and resident Indian trademarks instead of engg. coll., PhDs and GDP per capita do not qualitatively alter our results. Also from specification 3, we find that using 12, 2-digit SIC dummies instead of the 4 industry dummies also do not change out results by that much. Moreover, specification 4 shows that further controlling for the complexity of an innovation using controls for total number of inventors on a patent gives us qualitatively identical results.

We now test results 3 and 5. To this end we estimate period wide coefficients on $\log (1+$ backward self citations $), \log (1+$ forward self citations $)$ and $\log (1+$ forward other citations $)$. More precisely we estimate:

$\ln R_{i j p}=\delta_{0}+\alpha_{0}$ Period $I_{t}+\gamma_{0}$ Period $I_{t}+\mu_{1}$ Period $I_{t} * \log \left(1+\right.$ backward self citation $\left._{p}\right)+\mu_{2}$ Period

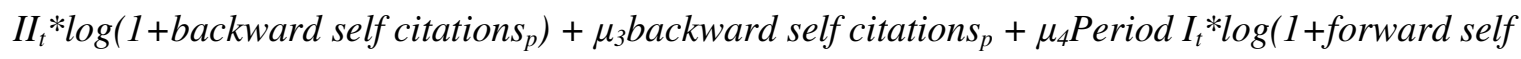

citation $\left._{p}\right)+\mu_{5}$ Period $I_{t} * \log \left(1+\right.$ forward self citation $\left._{p}\right)+\mu_{6}$ forward self citations $_{p}+\mu_{7}$ Period $I_{t} * \log \left(1+\right.$ forward other citations $\left._{p}\right)+\mu_{8}$ Period $I_{t} * \log \left(1+\right.$ forward other citations $\left._{p}\right)+\mu_{9}$ forward other

citations $_{p}+\Phi_{1} X_{i}+\Phi_{2} Z_{p}+\Phi_{3} K_{t}+\eta_{i j p}$

Result 3 suggests that $\mu_{2}+\mu_{3}<0, \mu_{1}+\mu_{3}<0$, and $\mu_{3}=0$. Moreover result 5 suggests that $\mu_{6}-\mu_{9}=0$ while $\mu_{4}+\mu_{6}-\mu_{7}-\mu_{9}>0$ and $\mu_{5}+\mu_{6}-\mu_{8}-\mu_{9}>0$. Once again we estimate (13) using OLS. As earlier, in specification 1 of table 5, we estimate (13) with 123 assignee fixed effects in addition to 4 industry dummies, engg. coll. and PhDs and GDP per capita. In specification 2, we additionally control for the for 
time varying assignee attributes such as $R \& D$ over sales and log(employees). In specification 3 , we additionally control for the complexity of the patent using the total number of inventors on a patent.

Results shown in table 5 and table 6 are in accordance with results 3 and 5. From specification 1, for instance one standard deviation increase in backward self citation is likely to decrease ratio inventors by $37 \%$ in period I, but only $17 \%$ in period II whereas a similar increase does not have a significant influence on ratio inventors after reforms in period III. Similarly an increase in proprietary nature of a patent increases ratio inventors in periods I and II whereas it has no effect after reform. Once gain using specification 1, one standard deviation increase in proprietaryness increases ratio inventors by $80 \%$ in period 1 and by $36 \%$ in period II whereas a similar change has no it has no substantial effect on ratio inventors after reforms.

Thus to summarize our empirical results, strengthening the patent regime, on average, increases the ratio of offshore inventors involved on a patent. While more incremental innovations to the firm appear to have more HQ scientists relative to a non-incremental (to the firm) innovation, proprietary innovations have more offshore scientists relative to a non-proprietary innovation.

As stated earlier, our main focus in not on the main effect of patent reform, but on these interaction effects. Interestingly, strengthening patent regimes have differential effects on how innovative labor gets divided between the HQ and the foreign country- there is a smaller increase in the proportion of foreign scientists on proprietary innovations relative to non-proprietary innovations whereas the increase in foreign scientists is more dramatic for innovations that are incremental to the firm relative to those that are radical to the firm. While a number of explanations unconnected to patent reforms can explain the increase in offshore scientists, such as the growing talent base and economic dynamism of offshore destinations compared to HQ locations, such alternative explanations cannot explain the pattern of interaction effects we find for incremental and proprietary innovations.

\section{Robustness Checks}

\subsection{Results using alternate measure of IPR strength:}

It is plausible that our principal results were driven by an event different from the patent changes that took place in 1994 and 2004. To discount this possibility, we constructed a time-varying measure of strength of IP -- the percentage of IP cases of total IP cases that were awarded in favor of the holder of the intellectual property right. We constructed this measure as follows: we first counted the number of High Court, Supreme Court and Intellectual Property Appellate board (IPAB) cases relating to patent, 
trademark and copyright cases from $1947 .{ }^{11}$ We then classified each case as "for IP" if the case was decided in favor of the holder of the IPR. Likewise we classified a case as "against IP" if they were awarded in against the IPR holder. We use the proportion of cases that were awarded in favor of the IPR holder (for cases divided by total cases; henceforth proportion for) to proxy for the strength of IP. We replicated specifications 1 of table 4 and table 5 using this alternative measure for the strength of IP in table 7. We find that our principal results are qualitatively unchanged. Specification 1 of table 6 shows that 1 standard deviation increase in proportion for increases ratio inventors by $22 \%$. Other results are broadly similar to those reported in table 4 . Next using interaction terms, we test results 3 and 5 . The interaction term of proportion for with backward self citations is positive indicating support for result 3 . Results shown under specification 2, suggest that while on an average patents with higher backward self citations are likely to have a lower ratio inventors one standard deviation increase in proportion for increases ratio inventors by less. For instance, when proportion for is zero one standard deviation increase in backward self citations decreases ratio inventors by about $9 \%$, whereas when proportion for increases by one standard deviation, a similar increase in backward self citations decreases ratio inventors by only $8 \%$. Specification 2 also suggests that when IPR become stronger proprietaryness of a patent has a smaller positive effect on ratio inventors. Once again using specification 2 , when proportion for is zero one standard deviation increase in proprietaryness increases ratio inventors by about $40 \%$. However when proportion for also increases by one standard deviation, a similar increase in proprietaryness increases ratio inventors by only $38 \%$.

\section{$<$ Insert table 6 here>}

In unreported specifications we also conducted additional robustness check using an alternative dependent variable Indian invented patent=1 if the focal patent was exclusively invented by Indian scientists and found that our principal results were unchanged.

\subsection{Survey of MNE R\&D Managers in India}

As an additional robustness check, in order to understand how IP regime influences the R\&D strategies of MNEs, we surveyed R\&D center directors or project managers of $240 \mathrm{R} \& \mathrm{D}$ captive centers owned by MNEs in India.

We first asked for the managers' perceptions (on a 1-7 scale) of how confident they were that the IPR in India protected their innovation from leaking away to competitors. Respondents were equally divided between those who were confident of protecting their IP and commercializing it before their competitors and those who were not (121 confident vs. 119 diffident managers). We found no significant

\footnotetext{
${ }^{11}$ We considered cases that related to infringement, post grant oppositions and term extensions. Cases that were awarded in favor of the owner of the trademark, patent, copyright or trade secret were counted as judgments in favor of IP. Analogously cases awarded against the owner were counted as judgments against IP.
} 
difference in the level of project interdependence between the captive center and headquarters: $60 \%$ of confident managers and $64 \%$ of diffident managers chose high interdependence projects $(\mathrm{p}=0.9$ in a ttest). Interestingly, managers who thought patent protection was adequate (67\% of the respondents) were just as likely to offshore highly interdependent projects as those managers who believe IP protection is inadequate. Note both these are at variance with the mechanism highlighted by Zhao (2006) from an interdependence perspective.

On the other hand, we also found evidence for strong internal linkages in the form of involvement of HQ scientists and managers. Diffident managers were more likely to involve more HQ scientists or managers in their projects when compared to confident managers $(80 \%$ to $64 \%$, p-val=0.0001). Also, similar to findings in international economics (Bransetter et al, 2004), we found that confident managers were more likely to implement global $R \& D$ and product development projects at the offshore center relative to not confident managers who were more likely to offshore projects that were aimed at local markets ( $49 \%$ vs. $40 \%$, p-val $=0.04)$.

In line with our hypotheses, we also found that confident managers were more likely to offshore non-proprietary projects or projects that were equally valuable to competitors compared with diffident managers $(92 \%$ vs. $74 \%$, p-val $=0.001)$. Similarly, confident managers are more likely to offshore incremental projects than not confident managers $(47 \%$ vs. $26 \%$, p-val $=0.001)$.

Since we were using a survey instrument after reforms, we should note that the managers are facing exactly the same IP regime. The differences in participation of Indian scientists that support our hypotheses were generated by differences in perceptions regarding the strength of the IPR.

\section{DISCUSSION}

We use the recently implemented patent reforms in India as a natural experiment to understand different strategies that MNEs use to deal with weak IP protection while conducting R\&D in weak IP regimes. In an attempt to control for unobserved heterogeneity at the firm and country level, our estimation strategy compares variation within a firm over to time across three distinct periods of patent reforms in a single country. Like Zhao, (2006), we show that these different R\&D management strategies can effectively substitute for weak legal IP protection; we highlight two such mechanisms.

Perhaps not surprisingly our results suggest that, strengthening patent protection increases the involvement of foreign scientists on an $R \& D$ project. Interestingly enough, we also have two sets of findings that suggest that the nature of R\&D conducted by a MNE varies depending on the strength of the patent regime in the foreign location. First, we find that MNE managers are more likely to involve more home country scientists than foreign scientists from a weak IP country on incremental R\&D projects fearing larger knowledge leakage in these innovations. But when the IPR is stronger they appear to be 
more willing to involve foreign scientists even on an incremental (to the MNE) innovation. Second, we also find that MNE managers are more likely to involve more foreign scientists on a proprietary innovation than on a non-proprietary innovation when the IPR is weak. This is because a proprietary innovation may just be harder to expropriate by the foreign scientists. However when the IPR become stronger MNEs appear to be more willing to involve foreign scientists from a weak IP country even on a non-proprietary innovation.

These imply that a weak IPR is indeed a key consideration for MNE manager and matter not just to decide whether to involve an offshore scientist on an innovation but also to decide which innovations to use offshore scientists for. While these complement Zhao (2006) who makes the case of using interdependence between innovations as a managerial mechanism to reduce losses from IP leakage, our results also suggest that, that may only be a part of the story in answering the puzzle of why R\&D offshoring is prevalent despite weak IP protection. Our results thus have significant managerial implications especially for MNE managers that are looking to capitalize on relatively cheap innovation talent available in weak IP countries. An obvious managerial implication is that when IPR is weak, MNEs can use project selection to compensate for the lack of legal IP protection.

Our results have interesting policy implications. While our results do not testify to how the extent of knowledge spillovers increase when IPR is strengthened, our results do suggest that knowledge spillovers are likely to increase when patent laws are strengthened. If it is true that spillovers occur mainly through transfer of knowledge embodied in an individual, then stronger patents laws in the presence of weak trade secret laws should increase knowledge spillovers as MNEs are likely to involve more foreign scientists on collaborative $R \& D$ projects under stronger patent laws. Moreover, our results suggest that the strength of IPR can have profound impact on the nature of the knowledge that is transferred by MNEs to a foreign location.

As with most work, ours also has limitations. Our main limitation is imposed on us by the nature of the data. First, our results based on an analysis of a handful of patents. However our results appear robust to several alternative empirical specifications, which provides us confidence in these results. Also whether our results are generalizable or just very specific to India is also unclear.

Nonetheless, we believe the paper does contribute in a novel way to understanding the possible effects of strengthening patent protection in a country that hitherto had a weak IPR. Moreover, since our work is a natural experiment, we do not rely of indices that measure the strength patent protection, many of which have been subjected to intense scrutiny of late. We thus hope that our work urges more such work and provides deeper insights on implications of strengthening patent regimes. 


\section{References}

Anand, B., and A. Galetovic. 2004. Strategies that work when property rights don't. Advances in the Study of Entrepreneurship, Innovation, and Economic Growth 15: 261-304.

Anton, J. J, and D. A Yao. 2002. The sale of ideas: Strategic disclosure, property rights, and contracting. Review of Economic Studies 69, no. 3: 513-531.

Arora, A. 1996. Contracting for tacit knowledge: the provision of technical services in technology licensing contracts. Journal of Development Economics 50, no. 2: 233-256.

Arora, A., A. Fosfuri, and A. Gambardella. 2004. Markets for technology: The economics of innovation and corporate strategy. The MIT Press.

Arrow, K. 1962. Economic welfare and the allocation of resources for invention. 1962.

Bessen, J., and E. Maskin. 2000. Sequential Innovation. Patents, and Imitation.

Gupta, Anil K., and Vijay Govindarajan. 1991. Knowledge Flows and the Structure of Control within Multinational Corporations. The Academy of Management Review 16, no. 4 (October 1): 768-792. doi:10.2307/258980.

Haakanson, L., and R. Nobel. 1993. Determinants of foreign R\&D in Swedish multinationals. Research Policy 22, no. 5: 397-411.

Kogut, B., and U. Zander. 1993. Knowledge of the firm and the evolutionary theory of the multinational enterprise. Journal of International Business Studies 24, no. 4: 625-645.

Kuemmerle, W. 1996. Home Base and Foreign Direct Investment in Research and Development: An Investigation Into the International Allocation of Research Activity by Multinational Enterprises: a Thesis. Harvard University, Graduate School of Business Administration.

Lerner, J. 2002. Patent protection and innovation over 150 years. NBER Working paper.

Levinthal, D. A. 1990. Absorptive Capacity: A New Perspective on Learning and Innovation Wesley M. Cohen. Administrative Science Quarterly 35: 128-152.

Lewin, A. Y, S. Massini, and C. Peeters. 2009. Why are companies offshoring innovation? The emerging global race for talent. Journal of International Business Studies 40, 6: 901-925.

Maskus, Keith E., and Mohan Penubarti. 1995. How trade-related are intellectual property rights? Journal of International Economics 39(3): 227-248.

Papke, L. E, and J. M Wooldridge. 1996. Econometric methods for fractional response variables with an application to 401 (k) plan participation rates. Journal of Applied Econometrics 11, no. 6: 619632.

Rivkin, J. W. 2000. Imitation of complex strategies. Management Science 46, no. 6: 824-844.

Ronstadt, R. 1977. Research and development abroad by US multinationals.

Sakakibara, M. 2001. Do stronger patents induce more innovation? Evidence from the 1988 Japanese patent law reforms. RAND Journal of Economics 32, no. 1: 77-100.

Scherer, F. M., and S. Weisburst. 2005. Economic effects of strengthening pharmaceutical patent protection in Italy. Patents: Economics, Policy, and Measurement: 67-82.

Szulanski, G. 1996. Exploring internal stickiness: Impediments to the transfer of best practice within the firm. Strategic management journal 17, no. 1: 27-43.

Teece, D. J. 1986. Profiting from technological innovation: Implications for integration, collaboration, licensing and public policy. Research policy 15, no. 6: 285-305.

Thursby, J., and M. Thursby. 2006. Here Or There?: A Survey of Factors in Multinational R and D Location-Report to the Government-University-Industry Research Roundtable. Natl Academy Pr.

Zahra, S. A, and G. George. 2002. Absorptive capacity: A review, reconceptualization, and extension. Academy of management review 27, no. 2: 185-203.

Zander, Udo, and Bruce Kogut. 1995. Knowledge and the Speed of the Transfer and Imitation of Organizational Capabilities: An Empirical Test. Organization Science 6, no. 1 (January 1): 76-92.

Zhao, M. 2006. Conducting R\&D in countries with weak intellectual property rights protection. Management Science 52, no. 8: 1185. 
Figure 1 - Ratio of foreign inventors by year



Table 1 Patents by industry segment

\begin{tabular}{ccccccc}
\hline Industry & Period I & Proportion & Period II & Proportion & Period III & Proportion \\
\hline ICT & 66 & 0.14 & 836 & 0.42 & 1401 & 0.47 \\
Electronics & 60 & 0.13 & 530 & 0.26 & 757 & 0.25 \\
Pharmaceuticals & 223 & 0.48 & 386 & 0.19 & 405 & 0.14 \\
Chemicals and plastics & 38 & 0.08 & 67 & 0.03 & 94 & 0.03 \\
Non-US assignees & 220 & 0.48 & 1088 & 0.54 & 1414 & 0.48 \\
N & 460 & 0.17 & 2006 & 0.74 & 2975 & 1.09 \\
\hline
\end{tabular}

Notes: Period $1=1$ if the year in which the patent was file was between 1973-1994. Period $2=1$ if the patent was filed between 1995-2003. Period III=1 if the patent was filed after 2004. 
Table 2 Description of measures used

\begin{tabular}{|c|c|c|c|c|c|c|}
\hline Variable & Description & $\begin{array}{l}\text { Source of } \\
\text { variation }\end{array}$ & $\mathrm{N}$ & & Mean & Std. Dev \\
\hline $\log R$ & $\begin{array}{l}\text { Ln(1+Indian inventors })- \\
\ln (1+\text { non-Indian inventors })\end{array}$ & Patent & & 5388 & -0.19 & 0.99 \\
\hline Proportion for & $\begin{array}{l}\text { Number of cases awarded in favor } \\
\text { of IP from } 1947\end{array}$ & Time & & 5388 & 0.58 & 0.05 \\
\hline $\log (1+$ self backward cits. $)$ & $\begin{array}{l}\mathrm{Ln}(1+\text { no. of backward cits.) to } \\
\text { patents belonging to the same } \\
\text { assignee as in the focal patent }\end{array}$ & Patent & & 5388 & 0.38 & 0.64 \\
\hline $\log (1+$ other backward cits. $)$ & $\begin{array}{l}\mathrm{Ln}(1+\text { other backward cits.) for } \\
\text { every patent }\end{array}$ & Patent & & 5388 & 1.36 & 1.08 \\
\hline $\log (1+$ forward self citations $)$ & $\begin{array}{l}\text { \# of forward citations made by the } \\
\text { same assignee relative to the } \\
\text { number of forward self citations of } \\
\text { that filing year cohort }\end{array}$ & Patent & & 5388 & 0.19 & 0.26 \\
\hline $\begin{array}{l}\log (1+) \text { weighted forward } \\
\text { other citations }\end{array}$ & $\begin{array}{l}\text { \# of forward citations in log made } \\
\text { to the patent by other assignees } \\
\text { relative to the number of forward } \\
\text { citations of that filing year cohort }\end{array}$ & Patent & & 5388 & 0.38 & 0.57 \\
\hline PCT patent & $\begin{array}{l}1 \text { if the patent was filed as a PCT } \\
\text { patent with the USPTO }\end{array}$ & Patent & & 5388 & 0.04 & 0.18 \\
\hline $\log (R \& D$ over sales $)$ & $\begin{array}{l}\mathrm{R} \& \mathrm{D} \text { in dollars for the focal } \\
\text { assignee divided by the total } \\
\text { amount of sales for the assignee } \\
\text { for a given year. }\end{array}$ & $\begin{array}{l}\text { Firm, } \\
\text { year }\end{array}$ & & $4832^{\mathrm{a}}$ & 0.12 & 0.29 \\
\hline $\log ($ size $)$ & $\begin{array}{l}\text { \# employees for the assignee in a } \\
\text { given year. }\end{array}$ & $\begin{array}{l}\text { Firm, } \\
\text { year }\end{array}$ & & $4832^{\mathrm{a}}$ & 5.54 & 1.84 \\
\hline US assignee dummy & $\begin{array}{l}=1 \text { if the assignee on the patent } \\
\text { was a US resident }\end{array}$ & Patent & & 5388 & 0.50 & 0.51 \\
\hline Engg. coll. & $\begin{array}{l}\text { Lag \# engineering colleges in a } \\
\text { year per million Indian residents }\end{array}$ & Year & & 5388 & 1.08 & 0.50 \\
\hline $\mathrm{PhD}$ & $\begin{array}{l}\text { Lag \# PhDs awarded per million } \\
\text { residents }\end{array}$ & Year & & 5388 & 12.16 & 5.10 \\
\hline Resident patent applications & $\begin{array}{l}\text { Lag number of patent applications } \\
\text { made by Indian residents at the } \\
\text { Indian Patent Office in a year }\end{array}$ & Year & & 5388 & 3.23 & 1.17 \\
\hline $\begin{array}{l}\text { Resident trademark } \\
\text { applications }\end{array}$ & $\begin{array}{l}\text { Lag number of trademark } \\
\text { applications made by Indian } \\
\text { residents at the Indian Patent } \\
\text { Office in a year }\end{array}$ & Year & & 5388 & 67.30 & 20.18 \\
\hline Industry dummies & $\begin{array}{l}4 \text { dummy variables for ICT, } \\
\text { medical/pharmaceutical, } \\
\text { electronics and chemical/plastics } \\
\text { industries }\end{array}$ & Industry & - & & & \\
\hline Time dummy & $\begin{array}{l}35 \text { dummies one each for years } \\
1974 \text { through } 2009\end{array}$ & year & - & & & \\
\hline Firm fixed effects & 123 firm fixed effects & firm & - & & & \\
\hline
\end{tabular}

a We do not have R\&D and employee data for small startups. 
Table 3A - Effect of reform on share of Indian inventors

\begin{tabular}{|c|c|c|c|c|c|}
\hline & $\begin{array}{c}\text { Period } \\
\text { I 1975- } \\
1994 \\
\end{array}$ & $\begin{array}{c}\text { Period II } \\
1995-2003\end{array}$ & $\begin{array}{l}\text { Period III } \\
2004-2009\end{array}$ & $\begin{array}{c}\text { Diff } \\
\text { between } \\
\text { PII and PI } \\
\text { (5) }\end{array}$ & $\begin{array}{c}\text { Diff } \\
\text { between } \\
\text { PIII and } \\
\text { PII (6) }\end{array}$ \\
\hline & 5.40 & 6.11 & 6.42 & $0.71 * *$ & $0.31 *$ \\
\hline Ratio inventors & $(0.30)$ & $(0.13)$ & $(0.11)$ & $(0.33)$ & $(0.17)$ \\
\hline \multicolumn{6}{|c|}{$* * *$ Sig. at $1 \%$ level. $* *$ Sig. at $5 \%$ level. $*$ Sig. at $10 \%$} \\
\hline & $\begin{array}{c}\text { Period } \\
\text { I 1975- } \\
1994 \\
\end{array}$ & $\begin{array}{c}\text { Period II } \\
1995-2003\end{array}$ & $\begin{array}{l}\text { Period III } \\
2004-2009\end{array}$ & $\begin{array}{c}\text { Diff } \\
\text { between } \\
\text { PII and PI }\end{array}$ & $\begin{array}{c}\text { Diff } \\
\text { between } \\
\text { PIII and } \\
\text { PII }\end{array}$ \\
\hline \multirow[t]{2}{*}{ Low backward self cites. } & 5.79 & 6.28 & 6.41 & 0.49 & 0.13 \\
\hline & $(0.32)$ & $(0.22)$ & $(0.20)$ & $(0.39)$ & $(0.30)$ \\
\hline \multirow[t]{3}{*}{ High backward self cites. } & 3.41 & 5.83 & 6.36 & 2.42 & 0.53 \\
\hline & $(0.72)$ & $(0.22)$ & $(0.13)$ & $(0.75)$ & $(0.26)$ \\
\hline & - & & & & \\
\hline \multirow[t]{2}{*}{ Diff.(High - Low) } & $2.38 * * *$ & $-0.45^{*}$ & -0.05 & $1.93 * *$ & 0.40 \\
\hline & $(0.79)$ & $(0.27)$ & $(0.24)$ & $(0.85)$ & $(0.39)$ \\
\hline
\end{tabular}

*** Sig. at $1 \%$ level. ** Sig. at $5 \%$ level. * Sig. at $10 \%$. High category is when the number of backward self citations is above median

\begin{tabular}{|c|c|c|c|c|c|}
\hline & $\begin{array}{c}\text { Period } \\
\text { I 1975- } \\
1994\end{array}$ & $\begin{array}{c}\text { Period II } \\
1995-2003\end{array}$ & $\begin{array}{l}\text { Period III } \\
\text { 2004-2009 }\end{array}$ & $\begin{array}{c}\text { Diff } \\
\text { between } \\
\text { PII and PI }\end{array}$ & $\begin{array}{c}\text { Diff } \\
\text { between } \\
\text { PIII and } \\
\text { PII }\end{array}$ \\
\hline Low ratio & $\begin{array}{c}5.14 \\
(0.18)\end{array}$ & $\begin{array}{c}5.81 \\
(0.15)\end{array}$ & $\begin{array}{c}6.62 \\
(0.12)\end{array}$ & $\begin{array}{c}0.67 \\
(0.23)\end{array}$ & $\begin{array}{c}0.81 \\
(0.19)\end{array}$ \\
\hline High ratio & $\begin{array}{c}6.05 \\
(0.20)\end{array}$ & $\begin{array}{c}6.38 \\
(0.13)\end{array}$ & $\begin{array}{c}6.75 \\
(0.16)\end{array}$ & $\begin{array}{c}0.33 \\
(0.24)\end{array}$ & $\begin{array}{c}0.37 \\
(0.21)\end{array}$ \\
\hline Diff.(High - Low) & $\begin{array}{c}0.91 * * * \\
(0.26)\end{array}$ & $\begin{array}{l}0.57 * \\
(0.20)\end{array}$ & $\begin{array}{c}0.13 \\
(0.18)\end{array}$ & $\begin{array}{l}-0.34 \\
(0.33)\end{array}$ & $\begin{array}{l}-0.44 * \\
(0.27)\end{array}$ \\
\hline
\end{tabular}


Table 4 - OLS regressions of ratio inventors, main effect of reform

\begin{tabular}{|c|c|c|c|c|c|c|c|c|}
\hline \multicolumn{3}{|c|}{ Spec. 1} & \multicolumn{2}{|c|}{ Spec. 2} & \multicolumn{2}{|c|}{ Spec. 3} & \multicolumn{2}{|c|}{ Spec. 4} \\
\hline Period I dummy $-\alpha_{0}$ & $\begin{array}{r}-0.16 \\
(0.04)\end{array}$ & & $\begin{array}{c}-0.19 \\
(0.03)\end{array}$ & & $\begin{array}{r}-0.17 \\
(0.02)\end{array}$ & & $\begin{array}{c}-0.19 \\
(0.03)\end{array}$ & \\
\hline Period II dummy $-\nu_{0}$ & $\begin{array}{l}-0.12 \\
(0.04)\end{array}$ & ** & $\begin{array}{c}-0.13 \\
(0.03)\end{array}$ & & $\begin{array}{l}-0.12 \\
(0.04)\end{array}$ & $* * *$ & $\begin{array}{c}-0.11 \\
(0.04)\end{array}$ & **** \\
\hline $\log (1+$ backward self citations $)-\rho_{1}$ & $\begin{array}{l}-0.07 \\
(0.02)\end{array}$ & ${ }^{* * *}$ & $\begin{array}{c}-0.08 \\
(0.01)\end{array}$ & $* * *$ & $\begin{array}{l}-0.07 \\
(0.02)\end{array}$ & $* * * *$ & $\begin{array}{c}-0.05 \\
(0.01)\end{array}$ & $* * *$ \\
\hline $\log (1+$ backward other citations $)$ & $\begin{array}{r}0.07 \\
(0.01)\end{array}$ & $* * *$ & $\begin{array}{r}0.07 \\
(0.01)\end{array}$ & $* * *$ & $\begin{array}{r}0.08 \\
(0.01)\end{array}$ & $* * *$ & $\begin{array}{r}0.05 \\
(0.01)\end{array}$ & $* * *$ \\
\hline $\log (1+$ forward self citations $)$ & $\begin{array}{r}-0.06 \\
(0.01)\end{array}$ & $* * *$ & $\begin{array}{r}-0.06 \\
(0.01)\end{array}$ & $* * *$ & $\begin{array}{l}-0.05 \\
(0.01)\end{array}$ & $* * *$ & $\begin{array}{r}-0.06 \\
(0.01)\end{array}$ & $* *$ \\
\hline $\log (1+$ forward other citations $)$ & $\begin{array}{r}-0.09 \\
(0.02)\end{array}$ & $* * *$ & $\begin{array}{r}-0.10 \\
(0.02)\end{array}$ & $* * *$ & $\begin{array}{r}-0.08 \\
(0.02)\end{array}$ & $* * *$ & $\begin{array}{r}-0.11 \\
(0.03)\end{array}$ & $* * *$ \\
\hline PCT patent dummy & $\begin{array}{r}-0.06 \\
(0.07)\end{array}$ & & $\begin{array}{r}-0.03 \\
(0.02)\end{array}$ & & $\begin{array}{r}-0.04 \\
(0.04)\end{array}$ & & $\begin{array}{c}-0.02 \\
(0.07)\end{array}$ & \\
\hline Non-US assignee dummy & $\begin{array}{c}-0.21 \\
(0.04)\end{array}$ & *** & $\begin{array}{r}-0.20 \\
(0.02)\end{array}$ & $* * *$ & $\begin{array}{l}-0.19 \\
(0.02)\end{array}$ & $* * *$ & $\begin{array}{c}-0.19 \\
(0.04)\end{array}$ & **** \\
\hline $\log$ (engg. colleges) & $\begin{array}{r}0.28 \\
(0.08)\end{array}$ & ${ }^{* * *}$ & & & $\begin{array}{r}0.18 \\
(0.05)\end{array}$ & $* * * *$ & $\begin{array}{r}0.19 \\
(0.09)\end{array}$ & $* *$ \\
\hline $\log (\mathrm{PhD}$ awarded $)$ & $\begin{array}{r}0.04 \\
(0.02)\end{array}$ & * & & & $\begin{array}{r}0.04 \\
(0.01)\end{array}$ & ** & $\begin{array}{r}0.02 \\
(0.02)\end{array}$ & \\
\hline $\log ($ GDP per capita $)$ & $\begin{array}{r}0.39 \\
(0.04)\end{array}$ & ${ }^{* * *}$ & & & $\begin{array}{l}(0.33) \\
(0.03)\end{array}$ & $* * *$ & $\begin{array}{r}0.11 \\
(0.25)\end{array}$ & \\
\hline $\log ($ lag resident Indian patents apps) & & & $\begin{array}{r}0.36 \\
(0.06)\end{array}$ & & & & & \\
\hline $\log ($ resident TM $)$ & & & $\begin{array}{r}0.04 \\
(0.00)\end{array}$ & $* * *$ & & & & \\
\hline R\&D not reported dummy & & & & & $\begin{array}{r}0.99 \\
(0.72)\end{array}$ & & $\begin{array}{r}0.95 \\
(0.91)\end{array}$ & \\
\hline$(1-R \& D$ nor reported $) * R \& D$ over sales & & & & & $\begin{array}{r}0.06 \\
(0.01)\end{array}$ & $* * *$ & $\begin{array}{r}0.05 \\
(0.03)\end{array}$ & * \\
\hline Size not reported dummy & & & & & $\begin{array}{r}0.11 \\
(0.05)\end{array}$ & ** & $\begin{array}{r}0.01 \\
(0.18)\end{array}$ & \\
\hline$(1 \text {-size not reported })^{*} \log ($ size $)$ & & & & & $\begin{array}{r}0.06 \\
(0.08)\end{array}$ & & $\begin{array}{r}0.10 \\
(0.05)\end{array}$ & ** \\
\hline Constant & $\begin{array}{r}1.99 \\
(2.18)\end{array}$ & & $\begin{array}{r}1.05 \\
(1.38)\end{array}$ & & $\begin{array}{r}1.69 \\
(0.18)\end{array}$ & *** & $\begin{array}{l}-1.36 \\
(2.15)\end{array}$ & \\
\hline$\rho_{2}-\rho_{3}$ & $\begin{array}{r}0.03 \\
(0.02)\end{array}$ & * & $\begin{array}{r}0.04 \\
(0.02)\end{array}$ & $* *$ & $\begin{array}{r}0.03 \\
(0.02)\end{array}$ & * & $\begin{array}{r}0.05 \\
(0.03)\end{array}$ & * \\
\hline Adj. R-squared & 0.20 & & 0.20 & & 0.22 & & 0.24 & \\
\hline
\end{tabular}

Notes: * Sig. at $10 \%$ level; ** Sig. at 5\% level; ***Sig. at $1 \%$ level. Standard errors in parentheses. All specifications use 5388 observations and 123 firm fixed effects. Specifications 1, 2 and 4 use 4 industry dummies. Specification 3 uses 20-digit SIC code dummies instead of the industry dummies. Specification 4 use 3 more dummies one each for total inventors on the focal patent $<=2$, between 2 and 5 and between 5 and 10 respectively, the coefficients of which are 1.19 ( 0.11$)$, 1.01 ( 0.10$)$ and $0.55(0.05)$ respectively. 
Table 5 - OLS regressions of ratio inventors, main effect of reform

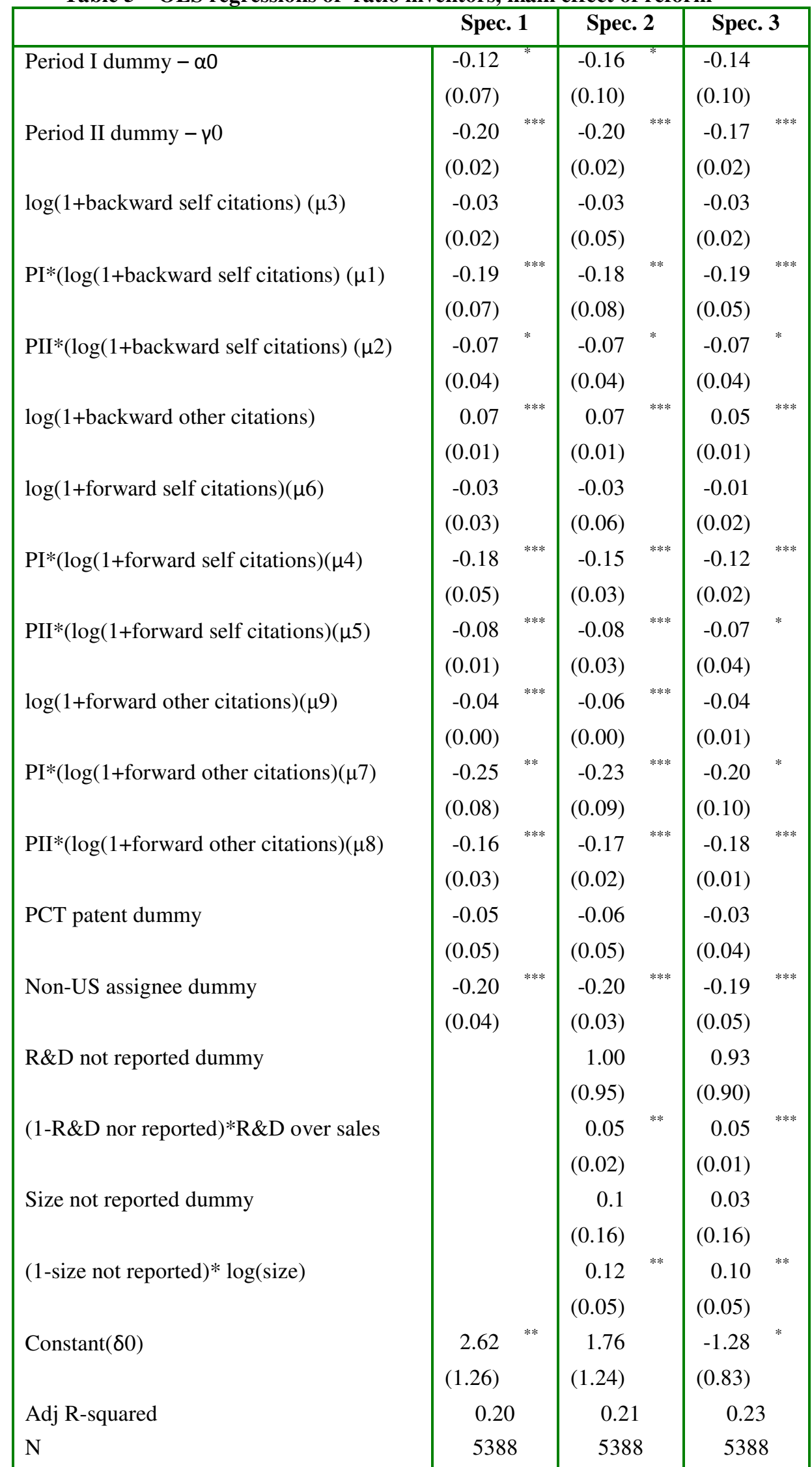

Notes: * Sig. at $10 \%$ level; ** Sig. at $5 \%$ level; ***Sig. at $1 \%$ level. Standard errors in parentheses. All specifications use 5388 observations, 123 firm fixed effects and 4 industry dummies. Specification 3 uses 3 additional dummies one each for total inventors on the focal patent $<=2$, between 2 and 5 and between 5 and 10 respectively. 
Table 6 - Tests for results 3 and 5

\begin{tabular}{|c|c|c|c|}
\hline \multirow[t]{2}{*}{$\mu_{1}+\mu_{3}<0$} & -0.22 & -0.21 & -0.22 \\
\hline & $(0.07)$ & $(0.09)$ & $(0.05)$ \\
\hline \multirow[t]{2}{*}{$\mu_{2}+\mu_{3}<0$} & -0.10 & -0.10 & -0.10 \\
\hline & $(0.04)$ & $(0.06)$ & $(0.04)$ \\
\hline \multirow[t]{2}{*}{$\mu_{6}+\mu_{4}-\mu_{7}-\mu_{9}>0$} & 0.20 & 0.22 & 0.25 \\
\hline & $(0.10)$ & $(0.11)$ & $(0.10)$ \\
\hline \multirow[t]{2}{*}{$\mu_{5}+\mu_{6}-\mu_{8}-\mu_{9}>0$} & 0.09 & 0.12 & 0.14 \\
\hline & $(0.04)$ & $(0.07)$ & $(0.05)$ \\
\hline \multirow[t]{2}{*}{$\mu_{6}-\mu_{9}=0$} & 0.01 & 0.03 & 0.03 \\
\hline & $(0.03)$ & $(0.06)$ & $(0.02)$ \\
\hline
\end{tabular}

* Sig. at $10 \%$ level; ** Sig. at $5 \%$ level; ***Sig. at $1 \%$ level. Standard errors in parentheses. 
Table 7 - OLS regressions of ratio inventors, main effect of reform

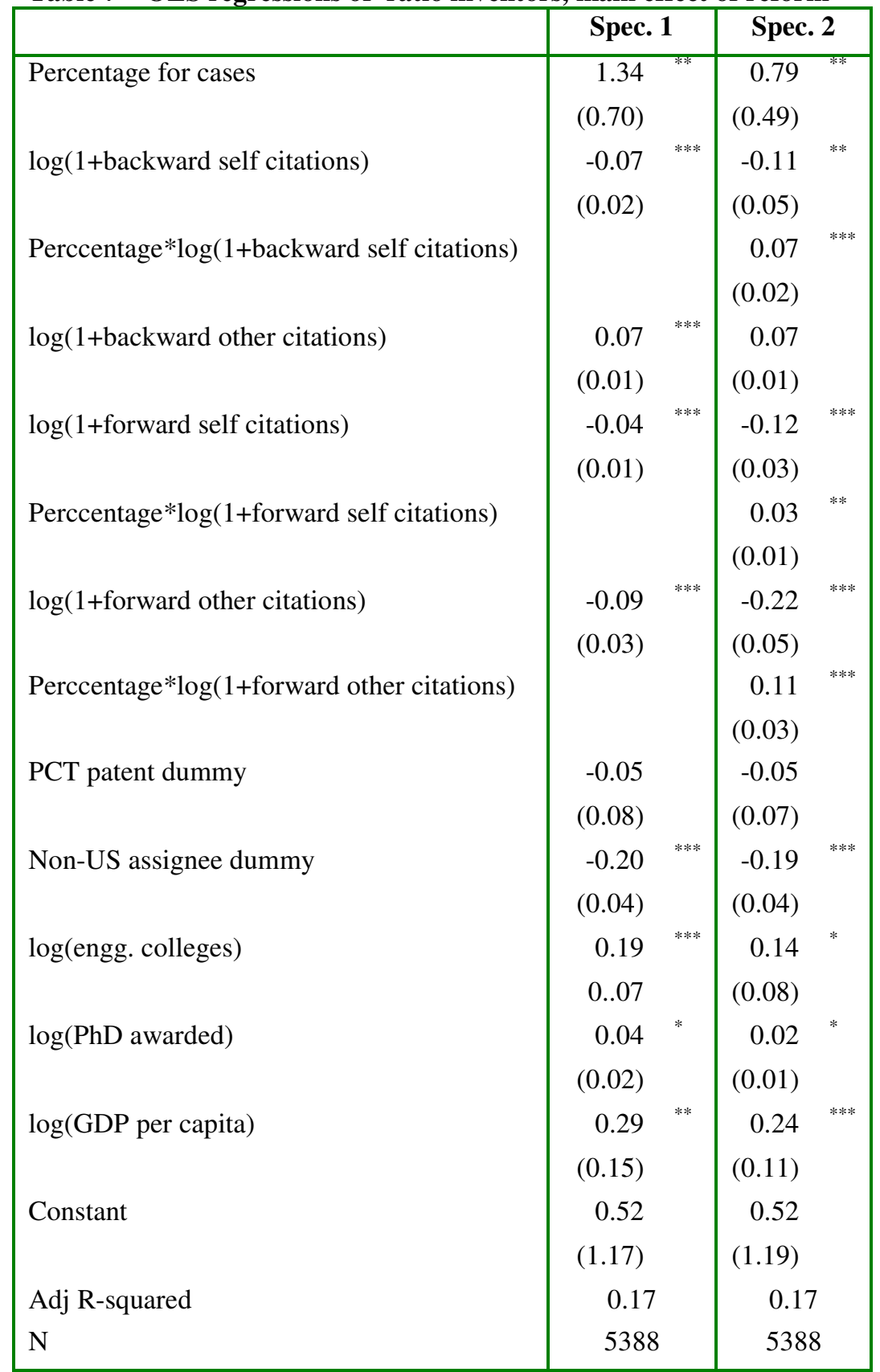

Notes: * Sig. at $10 \%$ level; ${ }^{* *}$ Sig. at $5 \%$ level; $* * *$ Sig. at $1 \%$ level. Standard errors in parentheses. All specifications use 5388 observations, 123 firm fixed effects and 4 industry dummies. Specification 3 uses 3 additional dummies one each for total inventors on the focal patent $<=2$, between 2 and 5 and between 5 and 10 respectively. 


\section{Appendix:}

Proof of propositions:

Recall that $\Pi=V(E, N)(1-p(\theta))^{N}-C E-\alpha N$ and the FOC are

$\frac{\partial \Pi}{\partial E}=V_{E}(1-p(\theta))^{N}=C$

$\frac{\partial \Pi}{\partial N}=(1-p(\theta))^{N} V_{N}+V(E, N)(1-p(\theta))^{N} \ln (1-p)=\alpha$

Using $\mathrm{c}=\mathrm{k} \alpha$

$\frac{\partial \Pi}{\partial E}=(1-p(\theta))^{N}\left[V_{E}-k V_{N}-V \ln (1-p(\theta))\right]=0$

$\frac{\partial \Pi}{\partial N}=(1-p(\theta))^{N}\left[k V_{N}+k V \ln (1-p(\theta))-V_{E}\right]=0$

The SOC are

$\frac{\partial^{2} \Pi}{\partial E^{2}}=\left(V_{E E}+V_{E} \ln (1-p(\theta))(1-p(\theta))^{N}\right.$ assumed to be $<0$.

$\frac{\partial^{2} \Pi}{\partial N^{2}}=\left(k V_{N N}+k V_{N} \ln (1-p(\theta))(1-p(\theta))^{N}<0\right.$ since $\ln (1-\mathrm{p})<0$

1. We show that $\frac{\partial N^{*}}{\partial \theta}>0$

$$
\frac{\partial N^{*}}{\partial \theta}=-\frac{\frac{\partial^{2} \Pi}{\partial N \partial \theta}}{\frac{\partial^{2} \Pi}{\partial N^{2}}}
$$

Using (B), $\frac{\partial^{2} \Pi}{\partial N \partial \theta}=\left[k V_{N}+k V \ln (1-p(\theta))-V_{E}\right] N(1-p)^{N-1} p_{\theta}-(1-p)^{N}\left[\frac{k v p_{\theta}}{1-p}\right]$

which is just $-(1-p)^{N}\left[\frac{k v p_{\theta}}{1-p}\right]>0$. Given that $\frac{\partial^{2} \Pi}{\partial N^{2}}<0, \frac{\partial N^{*}}{\partial \theta}>0$

2. We show that $\frac{\partial E^{*}}{\partial \theta}<0$

$$
\frac{\partial E^{*}}{\partial \theta}=-\frac{\frac{\partial^{2} \Pi}{\partial E \partial \theta}}{\frac{\partial^{2} \Pi}{\partial E^{2}}}
$$

Using (A), $\frac{\partial^{2} \Pi}{\partial E \partial \theta}=\left[V_{E}-k V_{N}-k V \ln (1-p)\right] N(1-p)^{N-1} p_{\theta}+(1-p)^{N}\left[\frac{k v p_{\theta}}{1-p}\right]$

which is just $(1-p)^{N-1} k v p_{\theta}<0$. Given that $\frac{\partial^{2} \Pi}{\partial E^{2}}<0, \frac{\partial E^{*}}{\partial \theta}<0$

3. We now prove result $1 \cdot \frac{\partial \Phi}{\partial \theta}>0$

Note that $\Phi=\frac{N^{*}}{E^{*}}$

Given (1) and (2) above, it follows that $\frac{\partial \Phi}{\partial \theta}=\frac{E^{*} \frac{\partial N^{*}}{\partial \theta}-N^{*} \frac{\partial E^{*}}{\partial \theta}}{E^{* 2}}>0$ 
4. We now prove result $2 \cdot \frac{\partial \Phi}{\partial \tau}<0$

First we show that $\frac{\partial N^{*}}{\partial \tau}<0 . \frac{\partial N^{*}}{\partial \tau}=-\frac{\frac{\partial^{2} \Pi}{\partial N \partial \tau}}{\frac{\partial^{2} \Pi}{\partial N^{2}}}$

$\frac{\partial^{2} \Pi}{\partial N \partial \tau}=(1-p)^{N}[k g \ln (1-p)]<0$. We have already shown that $\frac{\partial^{2} \Pi}{\partial N^{2}}<0$. Thus $\frac{\partial N^{*}}{\partial \tau}<0$

Next $\frac{\partial E^{*}}{\partial \tau}>0$. Note that $\frac{\partial E^{*}}{\partial \tau}=-\frac{\frac{\partial^{2} \Pi}{\partial E \partial \tau}}{\frac{\partial^{2} \Pi}{\partial E^{2}}}$

$\frac{\partial^{2} \Pi}{\partial E \partial \tau}=-(1-p)^{N}[k g \ln (1-p)]>0$. By assumption, $\frac{\partial^{2} \Pi}{\partial E^{2}}<0$. Thus $\frac{\partial E^{*}}{\partial \tau}>0$

Given these, it follows that

$\frac{\partial \Phi}{\partial \theta}=\frac{1}{E^{*}} \frac{\partial N^{*}}{\partial \theta}-\frac{\Phi}{E^{*}} \frac{\partial E^{*}}{\partial \theta}=-\frac{k g \ln (1-p)}{E^{*}}\left[\frac{1}{k V_{N N}+k V_{N} \ln (1-p)}+\frac{\Phi}{V_{E E}-k V_{E} \ln (1-p)}\right]<0$

5. We now show that $\frac{\partial^{2} \Phi}{\partial \theta \partial \tau}>0$

In (4) we have shown that when $\theta<1$, or when $p>1, \frac{\partial \Phi}{\partial \tau}<0$

However, when $\theta=1$, or when $\mathrm{p}=0$, it can easily be verified that $\frac{\partial \Phi}{\partial \tau}=0$ since $\frac{k \lg \ln (1-p)}{E^{*}}=0$

Thus $\left.\frac{\partial \Phi}{\partial \tau}\right|_{\theta=1}-\left.\frac{\partial \Phi}{\partial \tau}\right|_{\theta<1}>0$

6. $\frac{\partial \Phi}{\partial \delta}>0$

First we show that $\frac{\partial N^{*}}{\partial \delta}>0 \cdot \frac{\partial N^{*}}{\partial \delta}=-\frac{\frac{\partial^{2} \Pi}{\partial N \partial \delta}}{\frac{\partial^{2} \Pi}{\partial N^{2}}}$

$\frac{\partial^{2} \Pi}{\partial N \partial \delta}=-(1-p)^{N-1} k V p_{\delta}>0$. We have already shown that $\frac{\partial^{2} \Pi}{\partial N^{2}}<0$. Thus $\frac{\partial N^{*}}{\partial \delta}<0$

$\operatorname{Next} \frac{\partial E^{*}}{\partial \delta}<0$. Note that $\frac{\partial E^{*}}{\partial \tau}=-\frac{\frac{\partial^{2} \Pi}{\partial E \partial \delta}}{\frac{\partial^{2} \Pi}{\partial E^{2}}}$

$\frac{\partial^{2} \Pi}{\partial E \partial \delta}=(1-p)^{N-1} k V p_{\delta}<0$. By assumption, $\frac{\partial^{2} \Pi}{\partial E^{2}}<0$. Thus $\frac{\partial E^{*}}{\partial \tau}<0$

Given these, it follows that

$\frac{\partial \Phi}{\partial \delta}=\frac{1}{E^{*}} \frac{\partial N^{*}}{\partial \delta}-\frac{\Phi}{E^{*}} \frac{\partial E^{*}}{\partial \delta}=k V p_{\delta}\left[\frac{1}{\left(E^{*}(1-p)\right) k V_{N N}+k V_{N} \ln (1-p)}+\frac{\Phi}{\left(E^{*}(1-p)\right) V_{E E^{-}-k V_{E} \ln (1-p)}}\right]>0$

7. Finally we show that $\frac{\partial^{2} \Phi}{\partial \delta \partial \theta}<0$

In (6) above, we have shown that when $\theta<1$, or when $\mathrm{p}>1, \frac{\partial \Phi}{\partial \delta}<0$

When $\theta=1$, or when $\mathrm{p}=0$, it can easily be verified that $\frac{\partial^{2} \Phi}{\partial \delta \partial \theta}=0$ since $p_{\delta 1}=p_{1 \delta}=0$

Thus $\left.\frac{\partial \Phi}{\partial \delta}\right|_{\theta=1}-\left.\frac{\partial \Phi}{\partial \delta}\right|_{\theta<1}<0$ 